\title{
Do Age and Education Matter? Organizational Demography as an Influential Factor on Perceptions of a Learning Organization in Law Enforcement
}

\author{
Yvonne Hunter-Johnson \\ Southern Illinois University ${ }^{1}$
}

\begin{abstract}
Scholars and practitioners have identified many important factors that influence the development of a learning organization or employees' perception of that organization as a learning organization. However, in The Bahamas, there have been few studies that have empirically examined whether employees' perceptions are influenced by their educational level or by their age. This study focused on the perceptions of law enforcement officers of their organization as a learning organization at individual, team and organizational levels. Additionally, the study examined whether the officers' perceptions are influenced by their educational level and age. A total of 290 participants was surveyed and the data were analyzed using descriptive statistics and ANOVAs. The results from the study revealed that the officers' perceptions of the organization as promoting learning practices and cultures are neutral, revealing significant differences in their perceptions related to educational level.
\end{abstract}

\section{INTRODUCTION}

The continual investment in training and development by an organization often gives the illusion that the organization is a learning organization. However, such investment in training and development, or training itself, is only a characteristic of a learning organization and does not define an organization as a learning organization (Marsick \& Watkins, 1996). Investment in training, whether internationally or nationally, technical or academic, traditional or modern, is often implemented to enhance employee job-related competencies at an individual, group, or organizational level (Cascio, 2000; Noe, Hollenbeck, Gerhart \& Wright, 2006; Velada, Caetano, Michel, Lyons, \& Kavanagh, 2007). Further, the investment in training is often coupled with the expectation of promoting an organizational environment and/or culture that encourages continuous learning at the levels just mentioned (Hunter-Johnson \& Closson, 2011).

\footnotetext{
1 Yvonne Hunter-Johnson, Department of Workforce Education, Southern Illinois University, Carbondale,
} Illinois.

Acknowledgments: I wish to thank the administration and staff of the Royal Bahamas Police Force for their assistance and continued support.

E-mail: yohunter@mail.usf.edu

APA reference: Hunter-Johnson, Y. (2015). Do age and education matter? Organizational demography as an influential factor on perceptions of a learning organization in law enforcement. The International Journal of Bahamian Studies, 21(1), 57-73. http://dx.doi.org/10.15362/ijbs.v21i1.250 
Law enforcement, like other essential services, has a crucial responsibility to society. Such duties and responsibilities include, but are not limited to, protection of life and property, maintenance of law and order, and preservation of peace. To ensure that the officers are equipped with the knowledge, skills, and abilities to execute their functions and responsibilities in an effective and efficient manner, it is imperative that they are properly trained. In addition, they must be immersed in an atmosphere that promotes learning at all levels.

Within the professional arena and across disciplines, there has been evidence of a thirst for more knowledge related to learning organizations (Egan, Yang, \& Bartlett, 2004; Marquardt, 1996, 2002; Song, Joo, \& Chermack, 2009; Wang, Yang, \& McLean, 2007). Emphasis has been placed on cultural influence and learning organization, motivation, culture and commitment, leadership style, and quality of work. However, there are limited studies in the field of learning organizations that examine organizational demographic composition as an influential factor on employees' perception of their organization as a learning organization. On these premises, this study has been conducted with a view to determining whether organizational demographic composition (educational level and age) is an influential factor in employees' perception of their organization as one that promotes learning.

Numerous studies in the United States have focused on employees' perception of their organization as promoting learning practices and a learning culture. However, research on this topic in The Bahamas or in law enforcement in the country is limited.

Historically, organizational psychology literature supported organizational demographic composition as an influential factor of communication because people tend to communicate with those who are similar to themselves (Pfeffer, 1981, 1983; Simmel, 1980). However, scholars have ventured to demonstrate the connection between organizational demographic composition, employee turnover (Wagner, Pfeffer \& O’Reilly, 1984) and performance rating (Tsui \& O’Reilly, 1989). In recent years, there has been little empirical evidence demonstrating the connection of organizational demographic composition to employees' perception of their organization as a learning organization.

Law enforcement, like the military and other semi-military organizational structures, is grounded in a hierarchal structure. This hierarchal structure has a direct influence on the perception of seniority within the organization not only as it relates to years of service but also to age level. This structure creates a chasm between senior (older) and junior (younger) officers. As a result, much discussion has been given to senior officers' perception of training and development needs and the promotion of learning communities compared to the perceptions of younger officers. Consequently, entrance requirements in law enforcement are no longer based merely on physical appearance and strength but more on academics. This transition impacts officers' perception of the organization as educationally oriented.

Law enforcement is considered an essential service. On this premise, ongoing professional development, and an organizational culture that supports lifelong learning and promotes learning communities are paramount. Further, it is crucial that officers desirous of learning, whether formally or informally, immediately or in the future, perceive their organization as one that promotes learning. 
The purpose of this study was threefold. First, to determine whether law enforcement officers in the Bahamas perceive their organization as one that promotes learning practices and culture at an individual, team, and organizational level; second, to determine whether there was a distinction in the officers' perceptions, based on age and educational level; and, third, to address the gap in literature regarding organizational demographic composition as an influential factor on perceptions of a learning organization.

This study is crucial as a foundational platform. Not only will it determine whether the organization is perceived as a learning organization, but the findings from this study have the potential of being instrumental in identifying perceived vulnerabilities within the organization as a learning organization. Further, the study will reveal possible facets to be explored for improvement and development. Consequently, the findings from this study could contribute greatly to multidisciplinary perspectives of theory and practices for the fields of military, human resource development, general management, and public administration.

\section{Research Questions}

The guiding research questions for this study were as follows:

1. What are law enforcement officers' perceptions regarding their organization promoting learning practices, a learning culture, and a continuous learning environment at an individual, team, and organizational level?

2. Is there a distinction in law enforcement officers' perceptions regarding their organization promoting learning practices, a learning culture, and a continuous learning environment at an individual, team, and organizational level, based on age and educational level?

The theoretical framework that acts as the lens to illuminate and guide this study was the Watkins and Marsick (1997) framework. The model consists of two major components: the people who comprise an organization and the structures and culture created by the social practices of the organization. Additionally, it examined organizational learning on three distinct learning levels: individual, team, and organizational. The individual level comprises two dimensions of organizational learning: continuous learning, and dialogue and inquiry. The team and/or group level consists of team learning and collaboration. Lastly, the organizational level consists of four dimensions of learning: embedded systems, systems connection, empowerment, and leadership.

\section{Literature Review}

There has been a proliferation of literature related to learning organizations and organizational learning in the fields of human resource development, management, organizational development, adult learning, and school systems (Egan et al., 2004; Marquardt, 1996, 2002; Song et al., 2009; Wang, Yang, \& McLean, 2007) government agencies (Bales, 1993; Barth \& Bartenstein, 1998; Betts \& Holden, 2003; Brown \& Brudney, 2003; Corbett \& Kenny, 2001; Dilworth, 1996; Ferdinand, 2004; HunterJohnson, 2012; Hunter-Johnson \& Closson, 2012; McGrath, 2002; Tice, 2007). Although closely related and often used interchangeably, the concepts of a learning organization and organizational learning are distinctly different (Song et. al., 2009; Tsang, 1997).

According to Moharty and Kar (2012), a learning organization is a form of organization in and of itself whereas 
organizational learning describes activities or processes (of learning) that take place in organizations. They further contend that a learning organization needs specific activities and efforts to be consciously undertaken, while organizational learning exists naturally, without any specific efforts. Further, for organizational learning to be effective, learning must not merely take place at an individual level but arises through the interaction of individuals in groups and teams of different sizes. Garvin (2000), like Moharty and Kar, identified organizational learning as a collective process that "takes place in and through interaction with and between a number of people” (2012, p. 33). Ortenblad (2002) defines a learning organization as one that is continually expanding its capacity to create its own future. Within this type of organization, emphasis is placed on strategies geared towards enhancing organizational learning. Sugarman (2001) contends that a learning organization can be identified both internally (a culture that utilizes challenges and mistakes as a learning opportunity) and externally (one that adapts its external operations as a result of external factors). Watkins and Marsick (1993) on the other hand, identify a learning organization as "one that learns continuously and transforms itself and one that is characterized by total employee involvement in a process of collaboratively conducted, collectively accountable change directed towards shared values or principles" (1993, p. 118).

According to Garvin (2000), a learning organization is grounded on the principles of learning: perceiving and gathering information, interpreting, and acting based on the interpretation of the information. Gorelick, Milton, and April (2004) evidently supported the definition of a learning organization espoused by Watkins and
Marsick. They asserted that a learning organization is defined as:

...individuals, groups and teams continuously engaging in new processes to acquire, capture, store, disseminate, and reuse knowledge. Learning cannot be separated from performing and is a process that goes beyond time of entry into an organization or prescribed training session. (1993, p. 25)

Although there are some variations in the definitions of a learning organization by scholars, researchers, and practitioners in the field, there are some notable similarities. For instance, learning which results in some organizational change or transformation must be evident within the organization. Further, learning should occur at all three levels: individual, team and organizational.

\section{The Learning Organization}

Watkins and Marsick (1993) contend that many organizations can be classified as learning organizations. This includes private, public or non-profit, semi-military or military, academic or manufacturing organizations. In spite of their differences, however, these organizations share characteristics that are unique to learning organizations. They include (a) leaders who model calculated risk-taking and experimentation; (b) decentralized decisionmaking and employee empowerment; (c) skill inventories and audits of learning capacity; (d) systems for sharing learning and using it in business; (e) rewards and structures for employee initiative; (f) consideration of long-term consequences and impact on the work of others; (g) frequent use of cross-functional work teams; and (h) opportunities to learn; and (i) a culture of feedback and disclosure (Watkins \& Marsick, 1993).

Senge (2006), whose name is synonymous with the learning organization in the United 
States, further outlined five disciplines that are unique to learning organizations. They are (a) personal mastery; (b) shared vision; (c) mental models; (d) team learning; and (e) systems thinking.

Kerka (1995) later identified six characteristics of a learning organization. They include (a) provision of continuous learning opportunities; (b) use of learning to research organizational goals; (c) linkage of individual performance with organizational performance; (d) fostering of inquiry and dialogue that promotes a safe environment for people to share and take risks; (e) harnessing of creative tension as a source of energy and renewal; and (f) awareness of and continual interaction with their environment.

Although there is variation in the characteristics of a learning organization (Kerta, 1995; Senge, 2006; Watkins \& Marsick, 1993) the emerging themes reiterated by scholars are: (a) emphasizing communication regarding learning; (b) providing support and opportunities for learning; and (c) promoting learning at all levels (i.e., individual, team, and organizational).

\section{Levels of Learning}

According to Watkins and Marsick (1993), learning occurs at three distinct levels within an organization. Each level is clearly defined with distinct functions in the learning process. However, all levels are interdependent if an entity is to obtain the status of a learning organization.

The individual level is the foundational level. At this level, Marsick and Watkins explain, "learning takes place when disjuncture, discrepancies, surprises or challenges act as triggers that stimulate a response” (2003, p. 38). Individuals within the organization will then utilize their cognitive and affective understanding of the meaning of the initial trigger, and will select an appropriate strategy or action. After a plan or strategy has been identified by the individual, it is implemented and either works or does not work. Depending upon the outcome of the plan or strategy, the cycle is repeated (when the plan does not work, it is repeated until it is successful). At this particular level, individual actions are determined by factors such as skills, knowledge, and authority. Senge supports the concept of learning at the individual level though he also asserts that "individual learning does not guarantee organizational learning. But without it, no organizational learning occurs” (2006, p. 127).

Marquardt (1996), like Watkins and Marsick (1993), supports the concept of learning at the team level and identified characteristics that make learning at the team level successful. They include the idea that teams/groups must think and learn as an entity, must learn how to create and capture learning, and team/group learning should occur every time the team/group interacts. Marquardt further contends that within the team/group level, learning is self-managed, with the free flow of ideas. To ensure the success of a team/group in an organization, team members should be comfortable discussing their experience, whether negative or positive, as a learning opportunity within an organization.

Within the organizational level of learning, Marsick and Watkins (2003) contend that learning is a collective experience and a result of interactive and interdependent processes. This level differs from the individual and team levels because learning is prompted by such triggers as environmental jolts or surprises, new competitors, market downturns, new technology, customer dissatisfaction, or new demands. 


\section{METHOD}

The setting of the study was a law enforcement agency, the Royal Bahamas Police Force. This agency consisted of approximately 2,500 officers and 200 civilian staff and is solely responsible for the maintenance of law and order, preservation of peace, and protection of life and property throughout the 700 plus islands and cays in The Bahamas. With such an extensive and crucial responsibility, a large portion of the organization's budget is committed to training. In 1973, an academy was established whose sole responsibility was the training and development of law enforcement officers. At present, to ensure that officers are equipped with the knowledge, skills, and abilities to perform their duties effectively and efficiently, it is recommended that these officers attend training at the training academy. Training for these officers varies from technical training such as computer, first aid, driving, and firearms training to non-technical training which includes detective training, investigation, crime scene investigation, and developmental training for all ranks (Constables, Corporals, and Sergeants). In addition to local training, officers benefit from the opportunity to be trained regionally and internationally in other Caribbean Islands, the United States, the United Kingdom, and South America. However, despite the first-class training at the local academy, higher-ranking officers usually receive professional development training internationally. Regardless of the training location, officers are strongly encouraged to take professional development training for a variety of reasons, such as the need to be trained, the need to be promoted, and the need for new knowledge, skills, and abilities.

The research design used for this study was a non-experimental, quantitative approach.
The target population for this study was law enforcement officers in the Royal Bahamas Police Force.

The participants of this study were employed in the Royal Bahamas Police Force. The duties of the officers included, but were not limited to, the maintenance of law and order, preservation of the peace, and protection of life and property. This law enforcement agency had a hierarchical organizational structure consisting of ten ranks. The lowerlevel ranks include Constables, Corporals, and Sergeants. The higher-level ranks comprised Inspectors, Chief Inspectors, Assistant Superintendents, Superintendents, Assistant Commissioners, Deputy Commissioner, and a Commissioner. Officers ranged in age from 18 to 60 years. Males and females of varying academic levels, were deployed throughout the agency in approximately 100 distinct locations at a variety of stations, departments, and Family Island districts.

The inclusion criteria for the participants of this study were that they were between the ages of 18 and 60, employed as full-time, active employees, and sworn law enforcement officers. All participants were informed of their rights in conformity with the guidelines of the Institutional Review Board.

The sampling technique employed in this study was random sampling. To ensure population validity, at least 250 (10\%) of the 2,500 law enforcement officers were projected for this study. The anticipated sample size of 250 was adequate to obtain an effect size and power of at least 0.5 and 0.8 respectively. My intention was to have a large sample size because the bigger the sample size, the greater the power, thus minimizing standard error. Initially, 296 surveys were distributed and collected. However, I eliminated six (2\%) surveys as 
the participants failed to meet the inclusion criteria. Therefore, the data analysis was based on responses received from 290 law enforcement officers.

The instrument utilized in this study was the Dimension of Learning Organization Questionnaire-A (DLOQ-A), a subset of the original Dimension of Learning Organization Questionnaire (DLOQ, Marsick \& Watkins, 2003). This instrument was originally developed to measure the perceptions of learning practices and the learning culture of organizations. The seven dimensions of this instrument measure the organizational learning culture on the levels of individual, group/team, and organization (Marsick \& Watkins, 2003). It is a selfreport paper-and-pencil instrument that requires participants to rate their responses to the items. The DLOQ-A consists of 21 of the original 43 items of the DLOQ, which reflected the perception of the organization promoting continuous learning at an individual level (Questions 1-6), at a team/group level (Questions 7-9), and at an organizational level (Questions 10-21). The instrument is scored by asking study participants to rate their response on a scale of 1 (almost never) to 6 (almost always). Therefore, a score of 3 is interpreted as neutral. Any statement score above 4 suggests that the organization is perceived as a learning organization on that particular statement. Likewise, any statement score below 3 suggests that the organization is not perceived as a learning organization on that particular statement.

Although the DLOQ-A is a shorter version, it consists of three appropriate measures for each of the seven dimensions of the DLOQ and has better psychometric properties in terms of the formation of an acceptable measurement model. The DLOQ-A has been measured for reliability and validity in a variety of studies and across a variety of cultural contexts: the United States, Columbia, China, Taiwan, Korea, and Malaysia (Ellinger, Ellinger, Yang, \& Howton, 2002; Hernandez, 2003; Song et al., 2009; Yang, 2003; Yang, Watkins, \& Marsick, 2004). The results of these studies have verified the applicability of the DLOQA in different cultures, providing internal consistency of each item's reliability (coefficient alpha range from .71 to .91) and reliable factor structure of the dimensions of a learning organization (Lien et al., 2006).

The DLOQ-A was selected for use in this research, as opposed to the DLOQ, as a diagnostic tool that provides a comprehensive assessment of learning culture in seven dimensions, and provides additional information regarding making decisions related to intervention in the organization (Yang, 2003). However, because this research focuses on determining the theoretical relationships of the learning culture and other variables, such as organization performance, transfer of learning, and organizational capability, the shorter version (DLOQ-A) is recommended (Yang, 2003). Although the abbreviated version was used, the original concept remains valid. The seven dimensions measured on this instrument include (a) create continuous learning opportunities; (b) promote inquiry and dialogue; (c) encourage collaboration and team learning; (d) create systems to capture and share learning; (e) empower people toward a collective vision; (f) connect the organization to its environment; and (g) provide strategic leadership for learning (Hunter-Johnson, 2012). See Table 1 for an explanation of the three factors of the Dimension of Learning Organization Questionnaire. 
Table 1

Explanation of Three Factors of the DLOQ

\begin{tabular}{l|l|l}
\hline Factor & Dimension & Question \# \\
\hline Individual & Continuous learning & $1-6$ \\
\hline & Dialogue and Inquiry & \\
\hline Team/Group & Team Learning & $7-9$ \\
\hline & Collaboration & \\
\hline Organization & Embedded Systems & $10-21$ \\
\hline & Systems Connection & \\
\hline & Empowerment & \\
\hline & Leadership for learning & \\
\hline
\end{tabular}

First, the seven factors as indicated on the DLOQ-A, and as outlined above, were examined to determine if correlations existed. Then descriptive statistics, frequency distributions, and histograms were used to demonstrate the scores (low and high) of officers who perceived the organizational learning culture and practices as promoting continuous learning. Finally, after examining the responses from the DLOQ-A instrument, the responses were summarized descriptively, using the different methods of graphical and numerical statistics such as histograms and frequency tables. Based on the responses, I was able to identify the perceptions of the officers regarding organizational learning practices and whether the organization was promoting a continuous learning culture. To test for significant differences related to educational level and age, ANOVAs were used. These tests allowed me to determine if the perceptions regarding educational level and age differed.

\section{RESULTS}

Both genders were represented in the 290 law enforcement officers who participated in the study. The hierarchical rank structure ranged from Constable to Superintendent. The academic level of the law enforcement officers varied and included law enforcement officers with a high school diploma as well as officers who had obtained a Master degree. See Table 2 for demographic information on participants.

Table 2

Participants' Demographic Information

\begin{tabular}{l|l|l}
\hline Variable & $n$ & $\%$ \\
\hline Gender & & \\
\hline Male & 186 & 64 \\
\hline Female & 104 & 36 \\
\hline Education & & \\
\hline High School Diploma & 185 & 64 \\
\hline Associate degree & 50 & 17 \\
\hline Bachelor degree & 28 & 10 \\
\hline Master degree & 4 & 2 \\
\hline Other & 21 & 7 \\
\hline Rank & & \\
\hline Constable & 128 & 44 \\
\hline Corporal & 86 & 30 \\
\hline Sergeant & 45 & 15 \\
\hline Inspector & 16 & 6 \\
\hline Chief Inspector & 3 & 1 \\
\hline Assistant Superintendent & 10 & 3 \\
\hline Superintendent & 2 & 1 \\
\hline Note. N=290. & & \\
\hline
\end{tabular}

\section{Research Question 1}

What are the perceptions of law enforcement officers regarding their organization promoting learning practices, a learning culture and a continuous learning environment at an individual, team and organizational level?

The results and data revealed that of the 21 items on the questionnaire, 2 (9.52\%) means were lower than 3, with the highest mean being 3.85. At an individual level, there were 103 (36\%) participants with a response mean less than 3; at a team level 122 (42\%); at an organizational level 108 (37\%); and overall 114 (39\%). At an individual level there were 112 (39\%) participants with a response mean of 3 ; at a team level 86 (30\%); at an organizational level 85 (29\%); and overall 104 (36\%). At an individual level there were 75 (26\%) participants with a 
response mean greater than 4; at a team level 82 (28\%); at an organizational level 97 (33\%); and overall 72 (25\%). These response means imply that approximately 75 (26\%) of the participants perceived the organization as one that promoted learning practices, learning culture, and continuous learning. This suggests that there is room for improvement in promoting learning practices, a learning culture and continuous learning. See Table 3 for a summary of participants' responses to the questionnaire with a mean less than 3 and greater than 4 by dimension.

Table 3

Summary of Participants Responses

\begin{tabular}{l|l|l|l|l|l|l}
\hline Dimension & \multicolumn{2}{|c|}{$<3.00$} & \multicolumn{2}{c|}{$3.00-3.99$} & \multicolumn{2}{l}{$>4.0$} \\
\hline & $n$ & $\%$ & $n$ & $\%$ & $n$ & $\%$ \\
\hline Individual & 103 & 36 & 112 & 39 & 75 & 26 \\
\hline Team & 122 & 42 & 86 & 30 & 82 & 28 \\
\hline Organization & 108 & 37 & 85 & 29 & 97 & 33 \\
\hline Overall & 114 & 39 & 104 & 36 & 72 & 25 \\
\hline Note. $N=290$. & &
\end{tabular}

The results and data as shown in Table 4 reveal that overall, the law enforcement officers had a neutral perception of the organization as one that promoted learning practices, learning culture, and continuous learning at an individual level $(\mathrm{M}=3.26, S D$ $=0.91)$. The results at the team or group level reveal the same neutral perception ( $M$ $=3.10$, with a $S D=1.12$ ) as did the results at the organizational level $(\mathrm{M}=3.40$ with a $S D=1.07)$. However, this does not mean that the officers' individual scores were in this range.

Table 4

Descriptive Statistics by DLOQ-A Category Level

\begin{tabular}{l|c|c|c|c|c}
\hline Category & Question \# & Group M & $S D$ & Min & Max \\
\hline Individual & $1-6$ & 3.26 & 0.91 & 1.00 & 5.33 \\
\hline Team/Group & $7-9$ & 3.10 & 1.12 & 1.00 & 5.67 \\
\hline Organization & $10-21$ & 3.40 & 1.07 & 1.00 & 5.83 \\
\hline
\end{tabular}

\section{Research Question 2}

Is there a distinction in the perception of law enforcement officers regarding their organization promoting learning practices, a learning culture, and a continuous learning environment at an individual, team, and organizational level based on educational level and age?

For each ANOVA test by educational level and age, Levene's test of homogeneity of variance was run to determine if there was statistical evidence that this assumption had been violated on each dimension (individual, team, organizational, and overall). The results for an individual level by education revealed a $p=.122$ which suggests that the Levene's test was not significant. This implies there was no evidence that the assumption had been violated; the ANOVA tests were appropriate.

The results for team level by education revealed a $p=.121$ which suggests that the Levene's test was not significant. This implies there was no evidence that the assumption had been violated; the ANOVA tests were appropriate.

The results for organizational level by education revealed a $p=.483$ which suggests that the Levene's test was not significant. This implies there was no evidence that the assumption had been violated; the ANOVA tests were appropriate.

The results for overall level by education revealed a $p=.161$ which suggests that the Levene's test was not significant. This implies there was no evidence that the assumption had been violated; the ANOVA tests were appropriate.

The results for an individual level by age revealed a $p=.425$ which suggests that the Levene's test was significant. This implies there was evidence that the assumption appeared to be marginally violated. 
However, due to the sample size, the ANOVA test was robust to the violation, so that the results could still be reliable; the ANOVA tests were appropriate.

The results for team level by age revealed a $p=.223$ which suggests that the Levene's test was not significant. This implies there was no evidence that the assumption had been violated; the ANOVA test was appropriate. The results for an organization level by age revealed a $p=.545$ which suggests that the Levene's test was not significant. This implies there was no evidence that the assumption had been violated; the ANOVA test was appropriate. The results for overall level by age revealed a $p=.112$ which suggests that the Levene's test was not significant. This implies there was no evidence that the assumption had been violated; the ANOVA test was appropriate. $^{2}$

The range of mean scores by age was 2.94 to 3.67. The lowest mean was the age category of 31-40 years at a team level (2.94), and the highest mean was the age categories of 4150 years and under 20 years, at an organizational level (3.67). However, there was only one participant in the under 20 category. When the overall means were compared, there was a variation of 3.30 , 3.18, 3.54, 3.39, and 3.43. Table 5 illustrates dimension means and standard deviation by age.

\footnotetext{
${ }^{2}$ Assumption of normality. Normality and homogeneity are related. If one is violated, then the other is too. Since the sample size was large, this overrides any of the two assumptions if the assumptions are violated. Assumptions of independence. To ensure independence of observation while data were being collected, all participants completed their respective surveys independently, without communicating with me or any other participants. Further, no participant was allowed to include any identifying markings (name and/or badge number) on their respective surveys, to ensure they remained anonymous.
}

Table 5

Dimension Means and Standard Deviations by Age

\begin{tabular}{l|l|l|l|l}
\hline Age & Variable & $n$ & Mean & $S D$ \\
\hline$<20$ years & Individual & 1 & 3.67 & \\
\hline & Team & 3.00 & & \\
\hline & Organization & 3.42 & & \\
\hline & Overall & 3.43 & & \\
\hline $21-30$ years & Individual & 88 & 3.20 & 0.94 \\
\hline & Team & 3.15 & 1.15 & \\
\hline & Organization & 3.38 & 1.04 & \\
\hline & Overall & & 3.30 & 0.95 \\
\hline $31-40$ years & Individual & 111 & 3.20 & 0.88 \\
\hline & Team & 2.94 & 1.03 & \\
\hline & Organization & 3.24 & 1.05 & \\
\hline & Overall & & 3.18 & 0.91 \\
\hline & Individual & 70 & 3.43 & 0.84 \\
\hline & Team & & 3.29 & 1.13 \\
\hline & Organization & 3.67 & 1.06 & \\
\hline $51-60$ years & Overall & & 3.54 & 0.93 \\
\hline & Individual & 20 & 3.30 & 1.16 \\
\hline & Team & 3.12 & 1.37 & \\
\hline & Organization & 3.50 & 1.27 & \\
\hline & Overall & 3.39 & 1.20 & \\
\hline & & & &
\end{tabular}

Note. $N=290$.

The range of mean scores by educational level was 2.54 to 3.59 . The lowest mean was the educational category of Masters at an organizational level (2.54), and the highest mean was the educational category of High School Diploma at an organizational level (3.59). When the overall means were compared, there was a variation of 3.14, 2.93, 3.49, 2.71, and 2.94. See Table 6 for dimension means and standard deviation by educational level.

Data from this question were analyzed using ANOVA. The analysis for individual level and age revealed that there was no significant difference $-F(4,285)=0.87, p=$ .49 - between the mean responses in relation to age; hence, there was not sufficient evidence to conclude that there was a distinction in the perception of the organization learning practices, the learning 
culture and the promotion of continuous learning environment at an individual level, based on age.

Table 6

Dimension Mean \& Standard Deviation by Education Level

\begin{tabular}{|c|c|c|c|c|}
\hline Education & Variable & $n$ & Mean & $S D$ \\
\hline \multirow[t]{4}{*}{$\begin{array}{l}\text { High School } \\
\text { Diploma }\end{array}$} & Individual & 185 & 3.40 & 0.87 \\
\hline & Team & 3.24 & 1.13 & \\
\hline & Organization & 3.59 & 1.05 & \\
\hline & Overall & 3.49 & 0.93 & \\
\hline \multirow[t]{4}{*}{ Associate } & Individual & 50 & 3.14 & 0.88 \\
\hline & Team & 2.93 & 0.97 & \\
\hline & Organization & 3.20 & 0.99 & \\
\hline & Overall & & 3.14 & 0.88 \\
\hline \multirow[t]{4}{*}{ Bachelor } & Individual & 28 & 2.89 & 0.90 \\
\hline & Team & 2.77 & 1.03 & \\
\hline & Organization & 2.99 & 0.96 & \\
\hline & Overall & 2.93 & 0.84 & \\
\hline \multirow[t]{4}{*}{ Master } & Individual & 4 & 3.00 & 1.68 \\
\hline & Team & 2.83 & 1.73 & \\
\hline & Organizational & & 2.54 & 1.57 \\
\hline & Overall & 2.71 & 1.60 & \\
\hline \multirow[t]{4}{*}{ Other } & Individual & 21 & 2.90 & 1.07 \\
\hline & Team & 2.87 & 1.19 & \\
\hline & Organizational & 2.98 & 1.11 & \\
\hline & Overall & 2.94 & 1.05 & \\
\hline
\end{tabular}

Note. $N=290$.

The analysis for team level and age revealed that there was no significant difference$F(4,285)=1.10, p=.3556$-between the mean responses in relation to age; hence, there was not sufficient evidence to conclude that there was a distinction in the perception of the organization learning practices, the learning culture, and the promotion of continuous learning environment at a team level, based on age.

The analysis for organizational level and age revealed that there was no significant difference $-F(4,285)=1.78, p=.133$ between the mean responses regarding age; hence, there was not sufficient evidence to conclude that there was a distinction in the perceptions of the organization learning practices, the learning culture and the promotion of continuous learning environment at an organizational level based age.

The analysis for overall level and age revealed that there was no significant difference $-F(4,285)=1.58, p=.180-$ between the mean responses related to age; hence, there was not sufficient evidence to conclude that there was a distinction in the perceptions of the organization learning practices, the learning culture, and the promotion of continuous learning environment at an overall level, based on age. The analysis for individual level and education revealed that there was significant difference $-F(4,283)=3.42, p=.009-$ between the mean responses regarding education; hence, there was sufficient evidence to conclude that there was a distinction in the perceptions of the organization learning practices, the learning cultures and the promotion of continuous learning environment at an individual level, related to education.

The analysis for team level and education revealed that there was not a significant difference $-F(4,283)=1.90, p=.110$ between the mean responses regarding education; hence, there was not sufficient evidence to conclude that there was a distinction in the perceptions of the organization learning practices, the learning culture and the promotion of continuous learning environment at a team level, related to education.

The analysis for organizational level and education revealed that there was a significant difference $-F(4,283)=4.66, p=$ .001 -between the mean responses regarding education; hence, there was sufficient evidence to conclude that there 
was a distinction in the perceptions of the organization learning practices, the learning culture and the promotion of continuous learning environment at an organizational level, related to education.

The analysis for overall level and education revealed that there was a significant difference $-F(4,283)=4.44, p=.002$ between the mean responses regarding education; hence, there was sufficient evidence to conclude that there was a distinction in the perceptions of the organization learning practices, the learning culture, and the promotion of continuous learning environment at an overall level, related to education

The results of this study revealed neutralranking scores on the DLOQ-A by officers within this law enforcement agency. This suggests that for the most part, the officers had a neutral perception of their organization as one that promotes learning practices, a learning culture, and continuous learning with a mean at an individual level of 3.26, at the team level 3.10, and at the organizational level 3.40. Conversely, other studies conducted using the DLOQ-A in the international arena indicated that employees perceived their organization as one that promotes learning (Dymock, 2003; Hernandez, 2003; Weldy \& Gillis, 2010). However, in this study, the officers did not perceive their organization as one that did or did not promote learning. They had a neutral perspective.

Further, it is worth noting that despite the neutral perception, there were two questions that indicated officers had a negative learning experience. For example, Question 6 stated, "In my organization, people spend time building trust with each other" $(\mathrm{M}=$ 2.86).

Question 9 stated, "In my organization, teams/groups are confident that the organization will act on their recommendations” $(\mathrm{M}=2.91)$. The responses to these two questions suggest that as an organization, concerns exist regarding trust and, in particular, trust in relation to a learning environment. Additionally, there were some concerns regarding sharing of information (recommendations) made by officers, regardless of their rank, for the betterment of the organization, and the actual acceptance and implementation of those recommendations. In an attempt to address such concerns, some strategies that can be addressed as an organization include team-building exercises, setting norms of trustworthy behavior, and when possible, sharing the rationale behind difficult decisions (O’Neil, 2003).

The distinction in perception regarding educational level and age, the study revealed that there was no statistical significance regarding age at an individual level $F(4$, $285)=0.87, p=.49$; at the team level $F(4$, $285)=1.10, p=.356$; at the organizational level $F(4,285)=1.78, p=.133$. However, statistical significance existed regarding educational level at an individual level $F(4$, $283)=3.42, p=.009$, organizational $F(4$, $283)=4.66, p=.001$, and overall level $F(4$, 283) $=4.44, p=.002$. The results of this study revealed that their educational level influenced officers' perceptions. Evidently, officers who obtained a Bachelor degree $(M$ $=2.93, S D=0.84)$, Master degree $(\mathrm{M}=$ 2.71, $S D=1.60$ ) or other professional certifications $(M=2.94, S D=1.05)$ did not perceive the organization as one that promoted learning practices. Conversely, those officers who had obtained only a high school diploma or an Associate degree (introductory degree), perceived the organization as a learning organization that promoted a learning culture. This difference in perception by degreed officers can be attributed to a greater level of expectation by 
these officers due to a higher level of learning and exposure to learning, whether internationally or locally.

\section{DISCUSSION}

The law enforcement profession requires its employees be on the cutting edge of knowledge and be able to implement best practices in a given situation. On this premise, it is imperative that officers are immersed in a work environment that is supportive of learning, learning practices, and a culture reflective of supporting learning. Further, it is essential that the officer's perception of the organization is one that promotes learning and a learning culture. Within law enforcement, the hierarchal rank structure, like educational level, can influence this perception (HunterJohnson \& Closson, 2012). However, consistent with Watkins and Marsick's (1993) characteristics of a learning organization, there are some strategies that can be promoted within the organization to assist with promoting a learning organization, and hence, positively influence the perception of the officers within this organization once implemented; for instance, sharing of information, rewards and initiatives structures, decentralization of information, systems for sharing learning and using it in the organization, and presenting opportunities from which to learn.

Within this organization, in order to be recognized as a learning organization, it is recommended that sharing of new knowledge, whether formally or informally, be implemented via a knowledge management system. This would address the need for sharing information not only in a training environment, but information necessary to enhance the day-to-day duties and responsibilities of officers. Subsequently, it should also be incorporated in the organizational policies and/or procedures that officers attending training, whether locally or internationally, are required to share the knowledge learned in that training environment with others in the work environment. Further, any changes in organizational policies and procedures, initiatives of the Commissioner of Police or the government should be shared not only in written communication but also verbally through activities such as workshops, seminars, or organizational announcements.

In an attempt to recognize and promote learning practices and a learning culture within this organization, it is suggested that the organization implement a system that recognizes and rewards learning. Such a system can demonstrate a direct linkage of pay to knowledge or educational level; accelerated promotions; financial rewards (increments, salary increase, tuition fee reimbursement). It can also build learning incentives into work and individual development plans; and, as an organization, it can celebrate the learning achievements of its employees (Hunter-Johnson, 2012; O'Neil, 2003). Further, there should be an up-to-date database system that would track and assess the level of learning and educational achievements (academic or professional development) undertaken by employees with a view to applying this knowledge within the organization for its overall enhancement.

Law enforcement, like most military and semi-military organizations, has a hierarchal rank structure. As a result of this structure, organizational information, in most instances, is not effectively communicated throughout the ranks, which can influence the perception of its employees regarding information being disseminated. On this premise, it is imperative that information in this organization be decentralized.

Since law enforcement is an essential 
service, officers must be provided with opportunities to learn. There should be some process that identifies what works within the organization and what does not. Officers should be exposed to best practices, tried and proven practices regarding preventative and crime-fighting techniques, communityoriented policy, and technological advances. These lessons can be shared within the training academy during training exercises, seminars, workshops, panel discussions, department meetings, or after action reviews. It is important that the organization foster inquiry and dialogue by promoting a safe environment in which people can share and take risks (Kerta, 1995).

\section{CONCLUSION}

The purpose of this study was to determine Bahamian law enforcement officers' perception of their organization in terms of whether it promoted learning practices and a learning culture at an individual, team, and organizational level. Further, the purpose was to determine if there was a distinction in their perceptions based on age and educational level. This study provided confirmation that the officers had a neutral perception of their organization promoting learning practices and a learning culture, and that educational level was statistically significant. The study provided insight into the measures an organization can undertake in order to be recognized as one that promotes learning.

\section{REFERENCES}

Bales, B. V. (1993). Developing executives for the learning organization: a study of Texas state agency executives (Doctoral dissertation). Available from ProQuest Dissertations and Theses. (ATT 941342)

Barth, T. J., \& Bartenstein, J. (1998). Fostering a learning, innovative government: The role of academic/practitioner collaboration. Public Manager, 27(1), 2125.

Betts, J., \& Holden, R. (2003). Organisational learning in a public sector organisation: A case study in muddled thinking. Journal of Workplace Learning, 15(6), 280-287. http://dx.doi.org/10.1108/136656203104885 75

Brown, M., \& Brudney, J. L. (2003). Learning organizations in the public sector? A study of police agencies employing information and technology to advance knowledge. Public Administration Review, 63(1), 30-43. http://dx.doi.org/10.1111/1540-6210.00262
Cascio, W. F. (2000). Costing human resources: The financial impact of behavior in organization. Cincinnati, $\mathrm{OH}$ : SouthWestern.

Corbett, B., \& Kenny, B. (2001). Appraisal and learning in a government agency. The Learning Organization, 8(1), 21-35. http://dx.doi.org/10.1108/096964701103665 16

Dilworth, R. L. (1996). Institutionalizing learning organizations in the public sector. Public Productivity \& Management Review, 19(4), 407-421. http://dx.doi.org/10.2307/3381001

Dymock, D. (2003). Developing a culture of learning in a changing industrial climate: An Australian case study. Advances in Developing Human Resources, 5(2), 182195. http://dx.doi.org/10.1177 /1523422303005002006

Egan, T., Yang, B., \& Bartlett, K. R. (2004). The effects of organizational learning culture and job satisfaction on motivation to 
transfer learning and turnover intention. Human Resource Development Quarterly, 15(3), 279-302.

http://dx.doi.org/10.1002/hrdq.20013

Ellinger, A. D., Ellinger, A. E., Yang, B., \& Howton, S. W. (2002). The relationship between the learning organization concept and firms' financial performance: An empirical assessment. Human Resource Development Quarterly, 13, 5-21. http://dx.doi.org/10.1002/hrdq.1010

Ferdinand, J. (2004). Power, politics and state intervention in organizational learning. Management Learning, 35(4), 435-450. http://dx.doi.org/10.1177/135050760404827 2

Garvin, D. A. (2000). Learning in action: A guide to putting the learning organization to work. Boston, MA: Harvard Business School Press.

Gorelick, C., Milton, N., \& April, K. (2004). Performance through learning: Knowledge management and practice. Waltham, MA: Butterworth-Heinemann

Hernandez, M. (2000). The impact of the dimensions of the learning organization on the transfer of tacit knowledge process and performance improvement within private manufacturing firms in Colombia. (Doctoral dissertation). Available from ProQuest Dissertations and Theses database. (AAT 9994101)

Hernandez, M. (2003). Assessing tacit knowledge transfer and dimensions of a learning environment in Colombian businesses. Advances in Developing Human Resources, 5(2), 215-21. http://dx.doi.org/10.1177/152342230300500 2009

Hunter-Johnson, Y. (2012). Perception of a learning organization and factors within the workplace that influence transfer of training. (Doctoral dissertation, University of South Florida). Retrieved from http://scholarcommons.usf.edu/etd/4335

Hunter-Johnson, Y., \& Closson, R. (2011, November). From the shooting range to the street: Training facilitators' perception on transfer of training. Paper presented at the meeting of American Association for Adult and Continuing Education, Indianapolis, Indiana.

Hunter-Johnson, Y., \& Closson, R. (2012). Adult educators' perceptions of their organization promoting learning practices and culture: A Caribbean law enforcement context. Adult Learning, 23(4), 178-187. http://dx.doi.org/10.1177/104515951245791 9

Kerka, S. (1995). The learning organization: Myths and realities. Retrieved from http://files.eric.ed.gov/fulltext/ED388802.pd $\mathrm{f}$

Lien, B. Y., Hung, R. Y., Yang, B., \& Li, M. (2006). Is the learning organization a valid concept in the Taiwanese context?

International Journal of Manpower, 27(2), 189-203.

http://dx.doi.org/10.1108/014377206106662 09

Marquardt, M. J. (1996). Building the learning organization. New York, NY: McGraw-Hill.

Marquardt, M. J. (2002). Building the learning organization: Master the five elements for corporate learning. Palo Alto, CA: Davis-Black.

Marsick, V. J., \& Watkins, K. E. (1996). Adult educators and the challenge of the learning organization. Adult Learning, 7(4), 18-20. http://dx.doi.org/ 10.1177/104515959600700409

Marsick, V., \& Watkins, K. (2003).

Demonstrating the value of an organization's learning culture: The 
dimension of the learning organization questionnaire. Advances in Developing Human Resources, 5(2), 132-151. http://dx.doi.org/10.1177/152342230300500 2002

McGrath, V. J. (2002). The learning organization: Implications and lessons for municipal government (Doctoral dissertation). Retrieved from ProQuest Dissertations and Theses database. (ATT 3077569)

Mohanty, K., \& Kar, S. (2012). Achieving innovation and success: Organizational learning. SCMS Journal of Indian Management, 9(1), 36-42. http://www.scmsgroup.org/scmsjim/pdf/201 2/SCMS\%20Journal\%20of\%20Indian\%20M anagement\%20January\%20-

\%20March\%202012\%20Issue.pdf\#page=38

Noe, R. A., Hollenbeck, J. R., Gerhart, B., \& Wright, P. M. (2006). Human resource management: Gaining a competitive advantage. (6th ed.). Boston, MA: McGrawHill Irwin.

O’Neil, J. (2003). Participant's guide for interpreting results of the dimensions of the learning organization questionnaire. Advances in Developing Human Resources, 5(2), 222-230. http://dx.doi.org/10.1177/152342230325137 1

Ortenblad, A. (2002). A typology of the idea of learning organization. Management Learning, 33(2), 213-30. http://dx.doi.org/10.1177/135050760233200 4

Pfeffer, J. (1981). Some consequences of organizational demography: Potential impacts of an aging workforce on formal organizations. In S. B. Klester, J. N. Morgan \& V. K. Oppenheimer (Eds.), Aging Social Change (pp. 291-321). New York:

Academic Press
Pfeffer, J. (1983). Organizational demography. Research in Organizational Behavior, 5, 299-357.

Senge, P. M. (2006). The fifth discipline: The art and practice of the learning organization. New York, NY: Doubleday.

Simmel, G. (1980). The sociology of Georg Simmel. Translated by K.H. Wolff. Glencoe, III: Free Press.

Song, J. H., Joo, B. K. B., \& Chermack, T. J. (2009). The dimensions of learning organization questionnaire (DLOQ): A validation study in a Korean context. Human Resource Development Quarterly, 20(1), 4364. http://dx.doi.org/10.1002/hrdq.20007

Sugarman, B. (2001). A learning-based approach to organizational change: Some results and guidelines. Organizational Dynamics 30(1), 62-76.

http://dx.doi.org/10.1016/S00902616(01)00041-9

Tice, C. (2007, February). Building the 21st century leader. Entrepreneur Magazine, 6469.

http://www.entrepreneur.com/article/173522

Tsang, E. W. K. (1997). Organizational learning and the learning organization. Human Relations, 50(1), 73-89. http://dx.doi.org/10.1177/001872679705000 104

Tsui, A. S., \& O’Relly, C. A. (1989). Beyond simple demographic effects: The importance of relational demography in superiorsubordinate dyads. Academy of Management Journal, 32(2), 402-423. http://www.jstor.org/stable/256368

Velada, R., Caetano, A., Michel, J. W., Lyons, B. D., \& Kavanagh, M. J. (2007). The effects of training design, individual characteristics and work environment on transfer of training. International Journal of Training and Development, 11(4), 282-294. 
http://dx.doi.org/10.1111/j.1468-

2419.2007.00286.x

Wagner, W. G., Pfeffer, J., \& O’Reilly, C. A. (1984). Organizational demography and turnover in top management groups.

Administrative Science Quarterly, 29, 74-92. http://dx.doi.org/10.2307/256366

Wang, X., Yang, B., \& McLean, G. N. (2007). Influence of demographic factors and ownership type upon organizational learning culture in Chinese enterprises. International Journal of Training \& Development, 11(3), 154-165. http://dx.doi.org/10.1111/j.14682419.2007.00278.x

Watkins, K. E., \& Marsick, V. J. (1993). Sculpting the learning organization: Lessons in the art and science of systemic change. San Francisco, CA: Jossey-Bass.

Watkins, K. E., \& Marsick, V. J. (1997). Dimensions of the learning organization. Warwick, RI: Partners for the Learning
Organization.

Weldy, T. G., \& Gillis, W. E. (2010). The learning organization: variations at different organizational levels. The Learning Organization, 17(5), 455-470. http://dx.doi.org/10.1108/096964710110598 31

Yang, B. (2003). Identifying valid and reliable measures for dimensions of a learning culture. Advances in Developing Human Resources, 5(2), 152-162. http://dx.doi.org/10.1177/152342230300500 2003

Yang, B., Watkins, K., \& Marsick, V. (2004). The construct of the learning organization: Dimensions, measurement, and validation. Human Resource Development Quarterly, 15(1), 31-55.

http://dx.doi.org/10.1002/hrdq.1086 